References.

1. Szabo L, et al. Epilepsia. 2012 Mar;53(3):565-70.

\title{
HUMAN METAPNEUMOVIRUS AND STATUS EPILEPTICUS
}

Investigators at Cincinnati Children's Hospital, OH, report 2 toddlers, ages 15 and 18 months, with human metapneumovirus (hMPV) infection who presented in status epilepticus and later developed respiratory failure. Both patients recovered over 2 weeks with no sequelae. Infection with hMPV should be considered as a cause of seizures or encephalitis with respiratory symptoms in infants and children. (Webster DL, Gardner AH, Dye TJ, Chima RS. Status epilepticus: a possible association with human metapneumovirus infection. Pediatrics 2014 Mar;133(3):e747-50).

COMMENTARY. Neurological complications of human metapneumovirus infection are not mentioned in the 2012 edition of the AAP Redbook [1], and a review of seizures and hMPV in PubMed uncovers few reports. One earlier study reports an incidence of $6.3 \%$ of hMPV cases associated with seizures compared to $0.7 \%$ of patients infected with RSV ( $\mathrm{p}=0.031)$. hMPV may be associated with a spectrum of CNS disease ranging from febrile seizure to status epilepticus and severe, fatal encephalitis [2].

\section{References.}

1. AAP. Human Metapneumovirus. In: Pickering LK, et al, eds. Red Book: 2012 Report of the Committee on Infectious Diseases. 29th ed. Elk Grove Village, IL: AAP; 2012:509-10.

2. Arnold JC, et al. Pediatr Infect Dis J. 2009 Dec;28(12):1057-60.

\section{ENCEPHALITIDES}

\section{HERPES SIMPLEX AND NMDA ENCEPHALITIDES}

Investigators at University of Texas Southwestern Medical Center, Dallas, TX, report 2 male patients, an infant and adult, with confirmed herpes simplex encephalitis (HSE) and anti-NMDA receptor antibody encephalitis. Testing for anti-NMDA receptor antibodies and autoimmune disorder is recommended in patients with persistent encephalopathy, regression after initial improvement, or persistent movement disorders. Neuronal infections such as HSV may trigger subsequent anti-NMDA receptor antibody formation. Concomitant treatment or testing for immune-mediated encephalitis is indicated when treating viral encephalitis. (DeSena A, Graves D, Warnack W, Greenberg BM. Herpes simplex encephalitis as a potential cause of anti-N-methyl-D-aspartate receptor antibody encephalitis report of 2 cases. JAMA Neurology 2014;71(3):344-6).

COMMENTARY. The association of herpes simplex and anti-NMDA receptor antibody encephalitides is reported in 5 prospectively diagnosed patients ( 2 female) with relapsing post-herpes simplex encephalitis [1]. In 3 further retrospectively studied patients with HSE and NMDAR antibodies the frequency of autoantibodies increased over time, suggesting that HSE triggers NMDAR antibodies and brain autoimmunity [1]. 
All prospectively identified patients were treated with a second course of IV acyclovir, and 4 received immunotherapy with improvement in 3.

\section{References.}

1. Armangue T, et al. Ann Neurol. 2014 Feb;75(2):317-23.

\section{CONTINUOUS EEG IN ENCEPHALITIS}

Investigators from Rady Children's Hospital of San Diego, CA, reviewed records from all 217 children enrolled in the California Encephalitis Project 2004-2011. At least one seizure was observed clinically or recorded on EEG in $100(46 \%)$ children. Diffuse slowing occurred in $88.9 \%$, focal abnormalities in $63.2 \%$, and epileptiform abnormalities in $57.3 \%$. Continuous EEG for at least 1 day in $54(25 \%)$ patients recorded a seizure in more than half of patients. In $22(10 \%)$ children, a seizure was recorded by continuous EEG after routine EEG had failed to record a seizure. Overall, a continuous EEG was more likely to capture a seizure, capture a subclinical seizure, or rule out an event as a seizure than routine EEG ( $<<0.0001$ ). (Gold JJ, Crawford JR, Glaser C, Sheriff H, Wang $\mathrm{S}$, Nespeca $\mathrm{M}$. The role of continuous electroencephalography in childhood encephalitis. Pediatr Neurol 2014 Apr;50(4):318-23).

COMMENTARY. Continuous EEG is an important diagnostic tool in the ICU, to identify nonconvulsive seizures or status epilepticus, aid in management of AED treatment, and to identify seizures in children with suspected encephalitis. An online survey of pediatric neurologists from 50 US and 11 Canadian institutions conducted in 2011 found the following common cEEG indications: altered mental status after status epilepticus (97\%), altered mental status of unknown cause $(88 \%)$. Median number of patients with cEEG per month per center increased from 6 per month in 2010 to 10 per month in 2011 in the US [1].

\section{References.}

1. Sanchez SM, et al. J Clin Neurophysiol. 2013 Apr;30(2):156-60.

\section{BRAIN TUMORS}

\section{COGNITIVE OUTCOME OF CRANIOPHARYNGIOMA}

Investigators from Carl von Ossietzky University, Oldenburg, and other centers in Germany, compared cognitive performance in a group of 15 patients with childhood craniopharyngioma and hypothalamic involvement and a group of 24 age- and intelligence-matched control subjects. IQ scores were mostly in the average range and not significantly different in patients and controls. Patients had significantly lower performance scores in tests of memory and executive functioning. Delayed recall performance was severely impaired in one-third of the patients. Compared with patients with low-grade hypothalamic involvement, those with high-grade involvement showed worse performance in executive functions and reduced functional aptitude for daily life actions. Preoperatively, only 1 patient was severely obese; postoperatively, most patients 